\title{
I. General Introduction to the Lists of Threatened Biotopes*, Flora and Fauna of the Trilateral Wadden Sea Area (Red Data Book)
}

\author{
H. von Nordheim, O. Norden Andersen, J. Thissen \& T. Merck
}

\section{INTRODUCTION}

The Wadden Sea Area extends from Den Helder in The Netherlands along the coast and the islands of the German Bight to Esbjerg in Denmark. It is a network of tidal areas, channels, sandbars, mudflats, salt marshes and islands covering an area of about 900000 ha and thereby constitutes the largest intertidal area in the world. About $10 \%$ of the area belong to Denmark, $60 \%$ to the Federal Republic of Germany and the remaining $30 \%$ to The Netherlands.

This report represents the first attempt to evaluate and assess comprehensively the present status of the biotope types, the biotope complexes and of selected groups of plants and animals in coastal and marine areas of the entire Wadden Sea Area of The Netherlands, Germany and Denmark, and the factors threatening these. Recently, a Red List of plant communities of the Wadden Sea area was published by Westhoff et al. (1993).

In order to make trend analyses that would enable us, for example, to control the efficiency of trilateral measures for environmental and nature protection, it is important that the biotopes and species groups included in the Red Lists are monitored within the framework of the Trilateral Monitoring and Assessment Program (TMAP). The Red Lists should be revised at regular intervals and, if possible, be extended to include additional species groups. Missing data or a lack of records in the Red Lists, i.e. of "threat factors“ or "status" in a subregion of the Wadden Sea as well as incomplete species lists of a certain group should call for scientist and research organizations as well as administrative bodies to fill these gaps of knowledge in the coming years by financing and conducting appropriate research activities.

\section{FUNCTION OF RED LISTS FOR THE TRILATERAL WADDEN SEA AREA}

The Red Lists presented here are, so far, only in very few cases based on exact knowledge of population size, trends and distribution that stems from specific long-term

\footnotetext{
- The terms "biotope" and "biotope type "are normally used in this book since they have a different meaning from the terms "habitat" or "habitat type" that are also rather common in scientific literature; see also chapter "Red List of Biotopes".
} 
scientific studies or regular monitoring procedures (the best data base available is for birds!). The lists are primarily status reports compiled from more or less isolated reports and investigations and of some long-term trend studies. Nevertheless, the lists can be used as an important instrument in nature conservation work and policy making. The lists can function as (see e.g. Asbirk \& Søgaard, 1991; Anonymous, 1994; Riecken \& Ssymank, 1993; von Nordheim \& Merck, 1995):

- an information source for political decision makers, officials and the public (e.g. NGO's);

- a signal to politicians and the general public to increase support for nature conservation;

- a guideline and reference system for management and monitoring in the area;

- a reference system for environmental impact assessment in physical planning processes; means to justify measures of biotope and species protection;

- an efficiency control for measures of nature and environmental protection;

- means of facilitating the identification of high priority species and biotope types that require immediate protection measures;

- means to assist the implementation of international nature conservation conventions, etc. (e.g. EU-Fauna-Flora-Habitat-Directive, Bonn Convention);

- means of detecting gaps in our knowledge concerning species distribution, quality status of biotopes, threat factors, etc.

Red Lists are thus of equal importance for protected and unprotected areas of the Wadden Sea. Conclusions may be drawn from the threat factors and the proposed protection measures, as described in the following chapters, for the management of the Wadden Sea area.

Thus, the function of the Red Lists of the Trilateral Wadden Sea Area has to be seen in the framework of other trilateral activities in particular the Trilateral Management Plan and the Trilateral Monitoring Programme. According to $\S 68$ of the Leeuwarden Declaration (LD) of the 7th Trilateral Governmental Conference on the Protection of the Wadden Sea (Leeuwarden, November 1994) the Red Lists will facilitate the implementation of the ecological targets as indicated in $\S \S 6$ and 7 of the LD.

\section{DELIMITATION OF THE AREA AND SELECTION OF SPECIES AND BIOTOPES}

\section{Delimitation of the Survey Area}

During the initial preparation stages of the Red Lists in 1993, the Wadden Sea Area was considered by the Working Group to be delimitated to the seaward side by the $20 \mathrm{~m}$ isobath, or a line approximately $20 \mathrm{~km}$ from the coast of the islands to the landward side by the sea dike ("winter dike") and by the limit of freshwater influence (salinity $=0 \%$ ) in the estuaries. In areas where no sea dike is present, such as the peninsula of Skallingen and areas around Ho Bugt, the coastline and its typical coastal biotopes form the landward delimitation. The survey area also covers all islands, but here again only typical coastal biotopes and their species are considered (see chapter II "Biotopes and Biotope Complexes").

In November 1994 the delimitation of the Wadden Sea Area was defined at the Leeuwarden Conference for the Trilateral Cooperation Area as follows: 
- seawards by a line situated three nautical miles from the baseline;

- landwards by the main dike or, where the main dike is absent, by the spring-high-tide watermark, however, including adjacent areas that are designated as Ramsar sites or EC-Birds Directive Special Protection Areas;

- in the estuaries by the brackish water limit.

This definition is to a large extent identical with that of the Working Group applied for most species groups. Nevertheless, in no list, except in the Red List of Birds, were adjacent terrestrial areas "which are designated as Ramsar sites or EC-Birds Directive Special Protection Areas" included in the study area. The Red Lists of biotopes and of benthic invertebrates and fishes refer to the seaward extension of the survey of 1993 (see the respective lists).

Four subregions are distinguished in the Red Lists:

NL The Netherlands

Nds Niedersachsen and Bremen

SH Schleswig-Holstein and Hamburg

DK Denmark

\section{Selection of Biotopes and species groups of animals and plants}

For the present Red Lists it was agreed by the Trilateral Red List Working Group to include only typical coastal and marine biotopes and those species which occur regularly and typically in these biotopes. However, they do not have to occur exclusively in the survey area.

Those biotope types that have been substantially altered due to human impacts, such as intensively farmed grasslands, arable fields, settlement areas, etc. as well as artificial biotopes such as coastal defence structures or harbor constructions, are not considered.

The species groups were selected not only due to their importance in the marine and coastal ecosystem but also according to the availability of data and of specialists on the various groups. Different approaches to the selection of species are mentioned in the introductions to the chapters of the respective lists (e.g. birds).

\section{STRUCTURE OF THE RED LISTS}

Apart from biotope types and complexes all species groups are included for which data were submitted from at least two subregions and each group is dealt with in a separate chapter.

\section{General Structure of the Chapters}

The chapter on the biotope types and each chapter on a species group has an introductory section followed by two lists. The introduction deals with the trilateral aspects for a specific group in the Wadden Sea Area as well as special features or problems concerning this group. Further, it contains, in some cases, remarks on a special geographical delimitation of the survey area for a specific group, on the additional categories used for a group, and on special recommendations for conservation measures for certain species or biotopes. 
Each chapter contains two lists:

(1) The Red List of Species or Biotopes of the Wadden Sea Area ${ }^{\bullet}$ : a comprehensive list of threatened species or biotopes that have a trilateral status of threat (i.e. data were available for at least two subregions). These are listed for each threat category separately;

(2) The List of Threatened Species or Biotopes of the Wadden Sea Area: a detailed list of species or biotopes that are threatened in at least one subregion of the Wadden Sea including all available data on threat categories, threat factors, etc.

\section{Systems of Threat Categories}

\section{Fauna and Flora}

In Denmark Red Lists of species have been compiled according to the 1988 IUCN system of categories (1988 IUCN Red Lists of Threatened Animals) with the addition of an "X" - category (i.e. demanding special care due to decline in population size), and an "A"- category (i.e. giving special responsibility due to the high proportion of the European population of species occurring in Denmark). In The Netherlands a system is applied that has been developed by the National Reference Centre for Nature Management (see e.g. Lina \& van Ommering, 1994). In Germany the category system of the Federal Agency for Nature Conservation (Blab et al., 1984) is normally used on federal level.

Since none of the available systems met fully the needs of the Trilateral Red List Working Group, the group agreed to establish and apply the new system of threat categories as shown in Table 1. This system is based on the new IUCN system version 2.0 (Mace et al., 1992), the German system (Blab et al., 1984), the Danish system (Asbirk \& Søgaard, 1991) and was compiled by the Department for Coastal and Marine Conservation of the Federal Agency of Nature Conservation.

The assessment and categorization of a species in a certain threat category is primarily based on a decline of individual numbers recorded for a longer period (at least 10 to 20 years, ideal is $50-100$ years; in case of extinct species an even longer period may be considered). By proceeding in this way a record or a documentation of natural cyclic population fluctuations can be largely excluded.

The specified threat categories document only the status of the populations of the selected species within the defined Wadden Sea area, whereas outside the area the species or biotope may be threatened to a greater or lesser degree. If possible, the threat categories are given in the lists for all four subregions of the Wadden Sea area.

The trilateral threat category for bird species was evaluated by the specialists concerned, during two working sessions, considering the numbers, abundances, trends and distribution patterns in the entire Wadden Sea area. In all other cases the trilateral threat category for a given species is derived from the calculation of the arithmetic mean of the threat categories given for the four subregions by converting the threat categories EX, $\mathrm{CR}, \mathrm{EN}, \mathrm{VU}$ and ${ }^{*}$ (see Table 1 ) into numbers $0,1,2,3$ and 4 and weighting the score ac-

- No Red List was compiled for the marine macroalgae because for the Dutch part of the Wadden Sea, but not for the Danish and German parts, species were also considered that grow on artificial hard substrate (e.g. sea walls, piers). 
cording to the approximate areas of the subregions NL: Nds: $\mathrm{SH}: \mathrm{DK}=3: 3: 3: 1$. The result was then converted back into a threat category. For these calculations the additional symbols $-, ?,-(?)$ and $\left({ }^{*}\right)$ (see Table 2 ) and the corresponding subregion(s) were not taken into account, except for adding a "?" to the trilateral category if the additional symbols ?, $-($ ?) and (") occur in the subregional lists. This also applies to the category "Susceptible" =SU because the low (rare) but not threatened numbers of a species in one or more subregions neither improve substantially the overall situation of a species that is endangered in the other subregion(s) nor make it worse if the species is common and not under actual threat in other subregion(s).

Denmark proposed only recently a different procedure: by giving the threat categories scores according to a logarithmic scale and by treating SU as the lowest degree of being under an actual threat $(0,1,2,4,8$ and 16 to EX, CR, EN, VU, SU and ' respectively). The subsequent procedure was identical to the one described above. This procedure often leads to a lower trilateral category of threat if different degrees of threats are given for the subregions. Furthermore, some rather common but regionally threatened species would be grouped on the Red Lists as SU, i.e. a rare species. Germany and The Netherlands did not agree to this proposal this time; nevertheless this may be reconsidered if a revised version of the Red Lists of the Wadden Sea Area is compiled in some years hence.

\section{Biotope types}

Here, an internationally new system of criteria, definitions and threat categories for biotope types, biotope complexes and large landscape units, explained in detail in the chapter on biotopes in this report, was applied (see Blab et al., 1995). It is to a large extent compatible with the new IUCN-system (vers. 2.0) of threat categories for species. It must be stressed that here, in addition to an assessment of the actual status of the biotope types ("loss of area"), also qualitative changes and the regeneration possibilities are evaluated.

\section{Threat Factors}

As far as possible, remarks concerning the reasons for endangerment (threat factors) and possible protection measures are included in the introductory parts to each list or as symbols in the lists themselves (see Table 2). This list of threat factors for species has been constructed on the basis of national lists of the three countries. A somewhat different system is used in the Red List of Biotope Types (see chapter II). The threat factors can be used as basic information, when developing specific measures regarding species and biotope protection within the framework of the compilation of the Trilateral Management Plan.

Acknowledgements. The coordinators wish to thank all colleagues in The Netherlands, Denmark and Germany and from the Common Wadden Sea Secretariat who have contributed actively or with constructive criticism to the compilation of this report. Without their profound interest and scientific knowledge this task could never have been completed. 


\section{REFERENCES}

Anonymous, 1994. Rode lijsten: Signalen over natuur. Natuurbeschermingsraad, Utrecht, $34 \mathrm{pp}$.

Asbirk, S. \& S. Søgaard (Eds), 1991. "Rødliste '90" - Særligt Beskyttelseskrae vende planter og dyr i Danmark. (Red Data book of threatened plants and animals in Denmark - with English summary). Miljø ministeriet, Skov- og Naturstyrelsen, København, 222 pp.

Blab, J., Nowak, E., Trautmann, W. \& H. Sukopp (Eds), 1984. Rote Liste der gefährdeten Tiere und Pflanzen in der Bundesrepublik Deutschland. Kilda, Greven, $270 \mathrm{pp}$.

Blab, J., Riecken, U. \& A. Ssymank, 1995. Proposal on a criteria system for a national Red Data Book of biotopes. - Landscape Ecol. 10, 41-50.

Lina, P. H. C. \& G. van Ommering, 1994. Rode lijst van bedreigde en kwetsbare zoogdieren in Nederland. IKC Natuurbeheer, Wageningen, $42 \mathrm{pp}$.

Mace, G., Collar, N., Cooke, J., Gaston, K., Ginsberg, J., Leader-Williams, N., Maunder, M. \& E. J. Milner-Gulland, 1992. The development of new criteria for listing species on the IUCN Red List. - Species 19, 16-22.

Nordheim, H. von \& T. Merck (Eds), 1995. Rote Listen der Biotoptypen, Tier- und Pflanzenarten des deutschen Wattenmeer- und Nordseebereichs. - SchrReihe Landschaftspfl. Natursch. 44, $139 \mathrm{pp}$.

Riecken, U. \& A. Ssymank, 1993. Rote Liste Biotope - Übersicht über bestehende Ansätze, Ziele, Möglichkeiten und Probleme. - SchrReihe Landschaftspfl. Natursch. 38, 9-23.

Westhoff, V., Hobohm, C. \& J. H. J. Schaminee, 1993. Rote Liste der Pflanzengesellschaften des Naturraumes Wattenmeer unter Berücksichtigung der ungefährdeten Vegetationseinheiten. - Tuexenia 13, 109-140.

Table 1. Definitions and criteria for the threat categories

Applicable to: Populations of taxa in the wild that are or have been reproducing regularly and whose populations are extinct, presumed extinct or have become endangered in a certain survey area within the past 10-100 years.

EX - Extinct or Presumed Extinct (Disappeared from the area)

Definition: A population of a taxon occurring in an area is defined as Extinct, Exterminated or Presumed Extinct when:

- it was still living in the area about 50 to 100 years ago

- and if there is a high probability and no reasonable doubt or it has been even proved that since then the last individual has died or moved away,

- or if exhaustive surveys in the area have failed to record an individual in its former range and/or known or expected habitats at appropriate times (taking into account diurnal, seasonal, annual patterns of behaviour) over an appropriate time frame, but for at least 10 years.

In case of reappearence of such taxon/population special protection should be granted.

CR - Critical (Under immediate threat of extinction)

Definition: A population of a taxon occurring in an area is defined as Critical when:

- it is facing an extremely high probability of extinction in the immediate future in the area providing that the causal factors continue to operate or protection measures are not carried out or they are stopped

- and if individual numbers in the area have reached a critical level due to a long continuous and distinct general decline recorded for at least 10 years or if individual numbers currently show an extremely high and rapid decline or if the taxon has already disappeared from the major part of its former range in the area,

- or if the taxon occurs only with few single individuals or with few isolated and small populations in the area (so-called "rare species") that are seriously threatened by extinction due to actual or expected disturbance or habitat destructions. 
(Table 1, continued)

\section{EN - Endangered}

Definition: A population of a taxon occurring in an area is defined as Endangered when:

- it is facing a high probability of qualifying for the "Critical" category in the near future throughout its range in the area providing that the causal factors continue to operate, protection measures are not carried out or they are stopped

- and if individual numbers in the area show a significant continuous and general decline throughout the range over a period of at least 10 years and/or the taxon has already disappeared regionally,

- or if individual numbers throughout the range are very low due to a serious decline in the past.

VU - Vulnerable

Definition: A population of a taxon occurring in an area is defined as Vulnerable when:

- it is facing a high probability of qualifying for the categories "Endangered " or "Critical" in the medium-term future providing that the causal factors (e.g. human impacts) continue to operate, protection measures are not carried out or they are stopped

- and if individual numbers in the area, although on a larger scale they may possibly be still fairly high, have declined locally, regionally or in large parts of the range over a period of at least 10 years or if the taxon has disappeared locally,

- or if individual numbers, although still fairly high in large parts of the range, are regionally or locally small or very small due to a distinct decline in the past.

\section{SU - Susceptible}

\section{Additional categories:}

Definition: The population of a taxon occurring in an area is defined as Susceptible, even if at present actual threats do not exist, and it does not qualify for the categories CR, EN, or VU, when:

- it was at any time a rare species in the area with only few individuals or small local populations,

- and/or it is rare in the area due to the fact that the area is at the edge of its distribution range,

- and if there is a probability, that it could become at once exterminated or extremely decimated by sudden unforeseen local disturbances or destructions of habitats.

\section{* - Not Endangered}

The population of a taxon occurring in an area is defined as Not Endangered when:

- it does not qualify for the categories EX, CR, EN, VU or SU.

\section{IR - International Responsibility}

This category can be applied to taxa for which the area has special significance due to international population aspects, irrespective of degree of endangerment (in the Red Lists of the Trilateral Wadden Sea Area it applies only to birds; see chapter XII: Birds). 
Table 2. Symbols used in the lists of fauna and flora

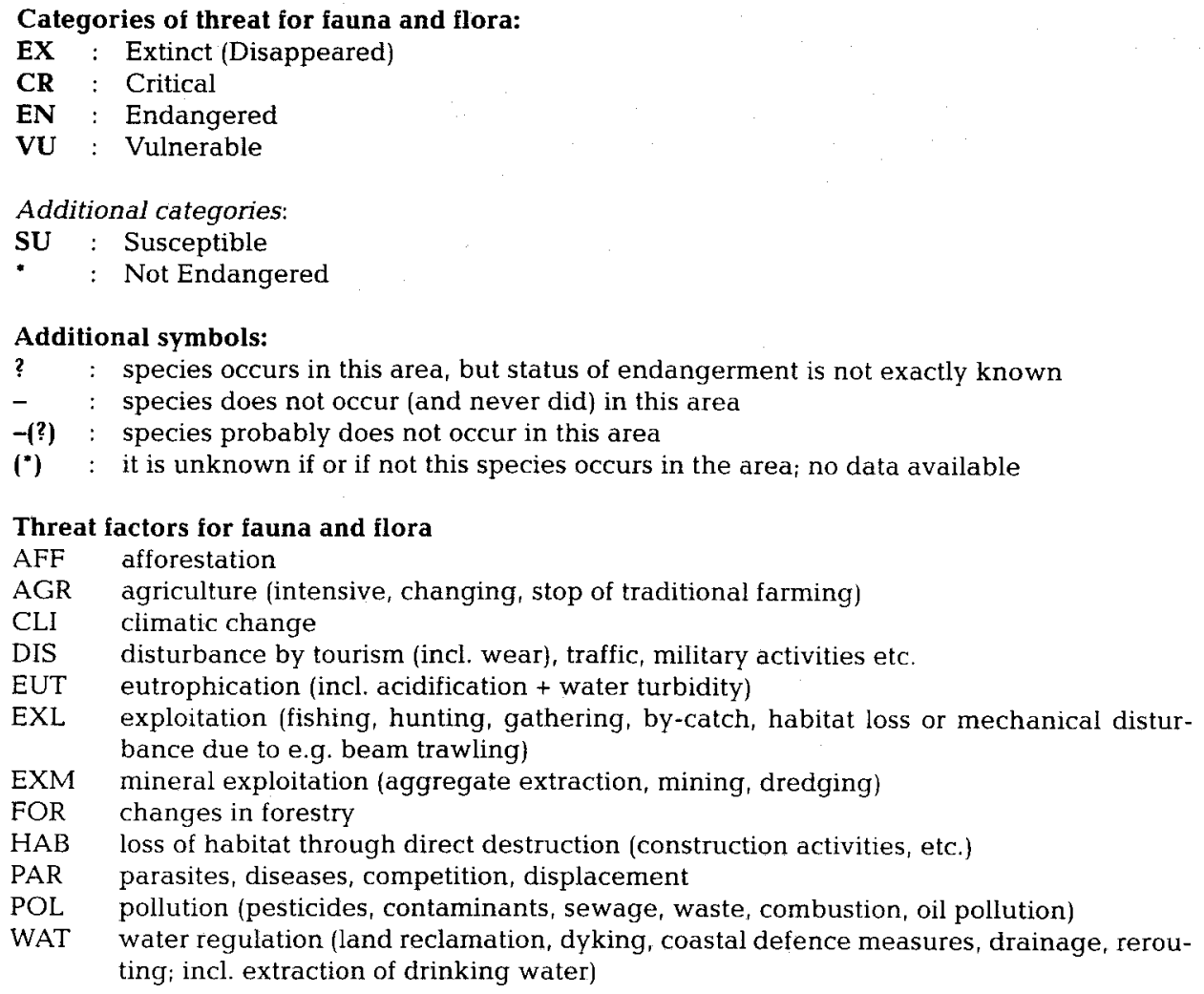

